\title{
Comparative analyses of classical phenotypic method and ribosomal RNA gene sequencing for identification of medically relevant Candida species
}

\author{
Constanza Giselle Taverna ${ }^{1 /+}$, María Eugenia Bosco-Borgeat ${ }^{1}$, Omar Alejandro Murisengo ${ }^{1}$, \\ Graciela Davel', Mariana Côrtes Boité2, Elisa Cupolillo', Cristina Elena Canteros ${ }^{1}$ \\ 'Departamento Micología, Instituto Nacional de Enfermedades Infecciosas Dr Carlos G Malbrán, Buenos Aires, Argentina \\ ${ }^{2}$ Laboratório de Pesquisa em Leishmaniose, Instituto Oswaldo Cruz-Fiocruz, Rio de Janeiro, RJ, Brasil
}

\begin{abstract}
As the distribution of Candida species and their susceptibility to antifungal agents have changed, a new means of accurately and rapidly identifying these species is necessary for the successful early resolution of infection and the subsequent reduction of morbidity and mortality. The current work aimed to evaluate ribosomal RNA gene sequencing for the identification of medically relevant Candida species in comparison with a standard phenotypic method. Eighteen reference strains (RSS), 69 phenotypically identified isolates and 20 inconclusively identified isolates were examined. Internal transcribed spaces (ITSS) and D1/D2 of the $26 \mathrm{~S}$ ribosomal RNA gene regions were used as targets for sequencing. Additionally, the sequences of the ITS regions were used to establish evolutionary relationships. The sequencing of the ITS regions was successful for 88\% (94/107) of the RS and isolates, whereas $100 \%$ of the remaining $12 \%$ (13/107) of the samples were successfully analysed by sequencing the D1/D2 region. Similarly, genotypic analysis identified all of the $R S$ and isolates, including the 20 isolates that were not phenotypically identified. Phenotypic analysis, however, misidentified 10\% (7/69) of the isolates. Phylogenetic analysis allowed the confirmation of the relationships between evolutionarily close species. Currently, the use of genotypic methods is necessary for the correct identification of Candida species.
\end{abstract}

Key words: Candida - ribosomal DNA - DNA sequence analysis

Candida species are fungal pathogens that can cause a wide range of superficial and deep mycoses, collectively known as candidiasis, that are commonly observed in immunocompromised patients. Candidaemia is the most clinically important Candida infection, both because is the most frequent yeast infection in hospitalised patients and because this infection results in significant mortality. The incidence has risen over the past decades as the number of immunocompromised patients has increased (Pfaller \& Diekema 2002, Falagas et al. 2010) and currently, candidaemia is the fourth most common nosocomial bloodstream infection in the United States of America (USA) (Pfaller et al. 1998, Edmond et al. 1999, Wisplinghoff et al. 2004).

Although Candida albicans remains the most frequently isolated species in human infection, more than $50 \%$ of candidaemias are due to infection with other Candida species (Price et al. 1994, Nguyen et al. 1996, Abi-Said et al. 1997, Trick et al. 2002, Hajjeh et al. 2004, Wisplinghoff et al. 2004). For example, in Argentina, $C$. albicans (38.4\%), Candida parapsilosis (26\%), Candida

This study was part of the CGT thesis for the Master in Science degree/ FIOCRUZ in collaboration with the ANLIS Dr Carlos G Malbrán. + Corresponding author: ctaverna@anlis.gov.ar

Received 6 September 2012

Accepted 12 December 2012 tropicalis $(15.4 \%)$ and Candida glabrata (4.3\%) are frequently isolated species (Cordoba et al. 2011).

The proper identification of Candida species is increasingly necessary, not only because the distribution of Candida species has changed, but also because these species differ in their susceptibility to antifungal agents (Pfaller \& Diekema 2002, Ellepola \& Morrison 2005). Accurate and rapid identification can facilitate the successful early resolution of infections and the subsequent reduction of morbidity and mortality (Pincus et al. 2007). The classical identification of fungi has been based on the morphological and physiological features of the sexual and/or asexual state. Because most medically important yeast species lack a sexual state and/or distinctive asexual morphological features, the correct identification of these species is often difficult and inconclusive when based solely on physiological traits. These morphological and physiological characteristics are often unstable, variable and subjective (Latouche et al. 1997). Furthermore, genetically diverse yeast species can yield similar phenotypic profiles, resulting in poor discrimination between unrelated yeast species (Sullivan et al. 1996). In this context, genotypic identification may be preferable as this method is faster and more accurate (Pincus et al. 2007).

The ribosomal RNA (rDNA) gene complex is largely used as a target in many polymerase chain reaction (PCR)-based assays because the complex is present in all microorganisms, occurs as tandem repeats of as many as 100-200 copies and contains highly conserved domains separated by variable domains, thus enabling the design of universal PCR primers for fungi (White et 
al. 1990, Kurtzman \& Fell 1998, Iwen et al. 2002, Pincus et al. 2007). Moreover, nucleotide-sequence heterogeneity within this complex may be used to phylogenetically classify microorganisms, including yeast species (Kurtzman \& Robnett 1998, Fell et al. 2000, Iwen et al. 2002).

The taxonomy of yeast and other fungal species has profoundly changed since the advent of DNA sequencing for the classification of microorganisms. Single gene sequences, such as those from the D1/D2 region of 26S rDNA or from the internal transcribed space (ITS) regions, are commonly used to identify yeast species (Kurtzman 2006, 2010). Recently, the sequence of the ITS region has been proposed to be a primary fungal barcode marker by the Consortium for the Barcode of Life (Schoch et al. 2012).

At present, the rDNA sequences of nearly all clinically relevant yeast species are available in public databases, such as GenBank (ncbi.nlm.nih.gov/genbank/) or the Centraalbureau voor Schimmelcultures (CBS) Yeast Database (cbs.knaw.nl), making it possible to genetically identify one unknown yeast isolate by comparing its rDNA sequences with those sequences in the database.

The aim of the current study was to compare a classical phenotypic method with rDNA sequencing for the identification of medically relevant Candida species. ITS sequences were also used to evaluate the genetic relationships between the samples analysed.

\section{MATERIALS AND METHODS}

Reference strains (RSs) and isolates - Eighteen RSs, which our laboratory commonly uses for identification and/or susceptibility testing, and 89 additional isolates (Supplementary data) were included in the study. The RS were obtained from the American Type Culture Collection, USA, the culture collection of the Carlos III Institute of Health, Spain, and the culture collection of the Department of Mycology of the National Institute of Infectious Diseases Dr Carlos G Malbrán, Argentina. Based on their phenotypic identification, isolates were selected from those received at the yeast identification laboratory from January 2009-December 2010. A total of 69 isolates of Candida species frequently isolated from patient in Argentina were included in the study (Rodero et al. 2005, Cordoba et al. 2011), as well as isolates with known resistance to common antifungal drugs. Also included were 20 isolates with ambiguous or inconclusive phenotypic identification, hereafter referred to as "not identified".

Phenotypic identification - The phenotypic identification was performed using standard methods (Kurtzman \& Fell 1998), including an assessment of growth on 19 carbon and two nitrogen sources by the auxanographic method, the fermentation of six carbohydrates, growth at $35^{\circ} \mathrm{C}$ and $37^{\circ} \mathrm{C}$, urea hydrolysis and morphological features. Discrimination between C. albicans and Candida dubliniensis was achieved using the agar tobacco test (Bosco-Borgeat et al. 2011).

DNA extraction - DNA extraction was performed according to the method reported by Möller et al. (1992), modified as previously described (Bosco-Borgeat et al. 2011). The DNA was preserved at $-20^{\circ} \mathrm{C}$ until use.
ITS amplification - The ITS1 (5'-TCCGTAGGTGAACCTGCGG-3') and ITS4 (5'-TCCTCCGCTTATTGATATGC-3') primers were used (White et al. 1990). The reactions were performed in a volume of $100 \mu \mathrm{L}$ containing $20 \mathrm{mM}$ Tris- $\mathrm{HCl}$ (pH 8.4), $50 \mathrm{mM} \mathrm{KCl}, 2 \mathrm{mM}$ $\mathrm{Mg}_{2} \mathrm{Cl} 2,5.2 \%$ DMSO, $0.2 \mathrm{mM}$ each of dATP, dCTP, dGTP and dTTP (Fermentas International, Inc), $0.1 \mu \mathrm{M}$ each of the primers ITS1 and ITS4, 1 U Taq DNA polymerase (Invitrogen-Life Technologies, Brazil) and $30 \mathrm{ng}$ of DNA. All of the amplifications were performed in an iCycler (Bio-Rad Laboratories, Inc) using the following parameters: $95^{\circ} \mathrm{C}$ for $7 \mathrm{~min}$, followed by 40 cycles at $95^{\circ} \mathrm{C}$ for $1 \mathrm{~min}, 54^{\circ} \mathrm{C}$ for $2 \mathrm{~min}, 72^{\circ} \mathrm{C}$ for $1 \mathrm{~min}$ and a final extension at $72^{\circ} \mathrm{C}$ for $10 \mathrm{~min}$.

Amplification of D1/D2 region of $26 \mathrm{~S} r D N A$ - The NL1 (5'-GCATATCAATAAGCGGAGGAAAAG-3') and NL4 (5'-GGTCCGTGTTTCAAGACGG-3') primers were used (White et al. 1990). The reactions were performed in a volume of $100 \mu \mathrm{L}$ containing $20 \mathrm{mM}$ Tris- $\mathrm{HCl}(\mathrm{pH} 8.4)$, $50 \mathrm{mM} \mathrm{KCl}, 2.5 \mathrm{mM} \mathrm{Mg} \mathrm{Cl}_{2}, 5 \%$ DMSO, $0.2 \mathrm{mM}$ each of dATP, dCTP, dGTP and dTTP, $0.1 \mu \mathrm{M}$ each of the primers NL1 and NL4, $1 \mathrm{U}$ Taq DNA polymerase and $30 \mathrm{ng}$ of DNA. All of the amplifications were performed in an iCycler using the following parameters: $95^{\circ} \mathrm{C}$ for $7 \mathrm{~min}$, followed by 40 cycles at $95^{\circ} \mathrm{C}$ for $1 \mathrm{~min}, 53^{\circ} \mathrm{C}$ for $2 \mathrm{~min}$, $72^{\circ} \mathrm{C}$ for $1 \mathrm{~min}$ and a final extension at $72^{\circ} \mathrm{C}$ for $10 \mathrm{~min}$.

Agarose gel electrophoresis - The PCR products were electrophoresed on $1.5 \%$ agarose gels in $40 \mathrm{mM}$ Tris-Acetate and $1 \mathrm{mM}$ EDTA buffer (1X TAE) for $1 \mathrm{~h}$ at $100 \mathrm{~V}$, stained with ethidium bromide $(10 \mu \mathrm{g} / \mathrm{mL})$ and then visualised under ultraviolet (UV) light and photodocumented using an LAS 3000 version 2.1 (Fuji Photo Film Co, Ltd). A GeneRuler 100 bp DNA Ladder (Fermentas Internationa, Inc) was used.

Purification of PCR products - The PCR products were purified using a PureLink PCR Purification Kit (Invitrogen). The products were then electrophoresed on $1.5 \%$ agarose gels in $1 \mathrm{X}$ TAE for $1 \mathrm{~h}$ at $100 \mathrm{~V}$, stained with ethidium bromide $(10 \mu \mathrm{g} / \mathrm{mL})$ and visualised under UV light. A ready-to-use MassRuler Express DNA Ladder, LR Reverse (Fermentas), was used.

DNA sequencing and editing - The PCR products were sequenced in the forward and reverse directions using the initial amplification primers and an automated DNA sequencer (Genetic Analyzer 3500, Applied Biosystems). The sequences were edited and the consensus sequences were obtained using BioEdit version 7.0.0 (Hall 1999). All of the sequences were deposited in the GenBank database; the GenBank accessions are listed in Supplementary data.

Genotypic identification by sequence similarity - Sequence similarity was obtained using either the BLASTN tool of the National Center for Biotechnology Information (NCBI) website (ncbi.nlm.nih.gov/BLAST/) (Library of Medicine, Bethesda, MD, USA) or the pairwise sequence alignment tool of the Fungal Biodiversity Centre on the CBS website (cbs.knaw.nl/collections/BioloMICSSequences.aspx) (The Netherlands). 
The identity of each isolate was determined based on the sequence similarity of the ITS regions, specifically using those results with $>97 \%$ similarity (Nilsson et al. 2008) and $99 \%$ coverage. When the similarity of the sequences of the ITS regions was $<97 \%$, the D1/D2 region of the 26S rDNA was sequenced using those results with 99\% similarity (Kurtzman 2006) and $99 \%$ coverage.

Phylogenetic analyses - All of the sequences of the ITS regions were aligned using the CLUSTALW program (Thompson et al. 1994) and a phylogenetic tree was constructed using MEGA version 4.0.2 software (Tamura et al. 2007). The neighbour-joining algorithm and the number-of-differences model were implemented. All of the gaps were excluded from the analysis and branch support was ascertained using 2,000 bootstrap replicates.

\section{RESULTS}

Genotypic identification by sequence similarity Supplementary data lists all of the identification results. The PCR using the primers ITS1 and ITS4 successfully amplified the ITS regions of all of the RS and isolates (data not shown). However, of the total 18 RS and 89 isolates, three RS and nine isolates yielded illegible sequences for their ITS regions for three replicates. Of the 80 isolates with legible sequences, 78 isolates had $\geq 97 \%$ similarity with the sequences deposited in the public databases. For the remaining two isolates and all three RS and nine isolates with illegible sequences for their ITS regions, sequencing of the D1/D2 region was performed. All of these RS and isolates yielded legible sequences and were $99 \%$ similar to the sequences deposited in the public databases.

In total, $15 \mathrm{RS}$ and 78 isolates were genotypically identified by sequencing the ITS regions alone. The remaining three RS and 11 isolates required sequencing of the D1/D2 region for identification. Two special cases, listed below, are comprised by the cases described in this paragraph.

Isolate 113940, which was not identified phenotypically, exhibited $94 \%$ similarity to Candida magnoliae SL040806 (AM408497.1, GenBank) using the BLASTN program and $99.7 \%$ similarity to Candida sorbosivorans CBS10293 (CBS website) for the ITS sequences. However, this isolate had $99 \%$ similarity to C. sorbosivorans CBS2250 (AY521567.1, GenBank) and 98\% similarity to C. magnoliae ESAB9 (AJ749827.1, GenBank) using the BLASTN program and $100 \%$ similarity to C. sorbosivorans CBS8768, CBS8824 and CBS10296 and 98.8\% similarity to C. magnoliae CBS2800 (CBS website) for the D1/D2 sequence. This isolate was thus identified as C. sorbosivorans.

Isolate 103840 , which was not identified phenotypically, had $94 \%$ and $99 \%$ similarity to Candida pseudorugosa XH1164 (DQ234792.1 and DQ234791.1, GenBank) for the ITS and D1/D2 regions, respectively. This isolate was identified as a Candida species closely related to C. pseudorugosa.

Comparison of phenotypic and genotypic identification - Table shows the concordance values obtained for the phenotypic and genotypic identifications. By comparing these methods, all of the RS and isolates phenotypically identified as C. albicans, C. dubliniensis, C. tropicalis, C. glabrata, Candida haemulonii, Candida kefyr, Candida krusei, Candida lusitaniae, Candida pelliculosa and Candida guilliermondii var. membranifaciens demonstrated $100 \%$ concordance with their genotypic identifications. In contrast, the phenotypic identification did not agree with the genotypic identification in seven cases: four $C$. guilliermondii were misidentified as Candida famata (isolates 113934-37), isolate 113891 (C. haemulonii var. vulnera) was misidentified as $C$. guilliermondii, isolate 113933 (Candida fermentati) was misidentified as $C$. guilliermondii and isolate 113916 (Candida orthopsilosis) was misidentified as $C$. parapsilosis.

All of the isolates with ambiguous or inconclusive phenotypic identification (that is, not identified) were genotypically identified by sequencing one or both of the target regions.

Phylogenetic analyses - The phylogenetic tree for the ITS sequences (Figure) exhibits different clusters that are composed of isolates belonging to the same species. One exception was the C. fermentati isolate (113933), which clustered in the C. guilliermondii group. These species have only a three-nucleotide difference in their ITS sequences (data not shown). A low-level sequence divergence was observed among the isolates in each cluster, although intraspecies diversity was observed for C. famata, C. haemulonii and C. lusitaniae. An analysis of the $C$. haemulonii cluster showed that $C$. haemulonii var. vulnera (isolate 113891) was included in a separate branch. When analysing the $C$. lusitaniae cluster, the level of sequence diversity may be compared with the interspecies divergence observed between $C$. albicans and C. dubliniensis or between C. parapsilosis and $C$. orthopsilosis, for example (Figure).

Certain species formed well-supported clades (bootstrap > 70) (Group A: C. albicans, C. dubliniensis, C. tropicalis, C. parapsilosis and C. orthopsilosis; Group B: C. famata, C. guilliermondii and C. fermentati; Group C: C. pseudorugosa and Candida rugosa; Group F: C. haemulonii and C. lusitaniae).

\section{DISCUSSION}

The advent of DNA sequencing has yielded many new tools for fungal identification that are used by taxonomists and non-taxonomists alike. However, certain factors should be considered when performing genotypic identification using rDNA sequencing. First, rDNA consists of tandem repeats, with as many as 100-200 copies (Kurtzman \& Fell 1998). Individual copies typically evolve nearly in unison, meaning that each gene copy shares the same set of mutations with the other copies. This uniformity arises from sequence homogenisation mechanisms that are collectively referred to as concerted evolution (Alvarez \& Wendel 2003). However, these mechanisms may be out of pace with variation-generating processes. It thus cannot be assumed that only one sequence type exists (Alvarez \& Wendel 2003). In our study, 12 specimens yielded an illegible ITS chromatogram, presumably because these specimens contained more than one type of 
TABLE

Concordance between phenotypic and genotypic identification of Candida spp isolates

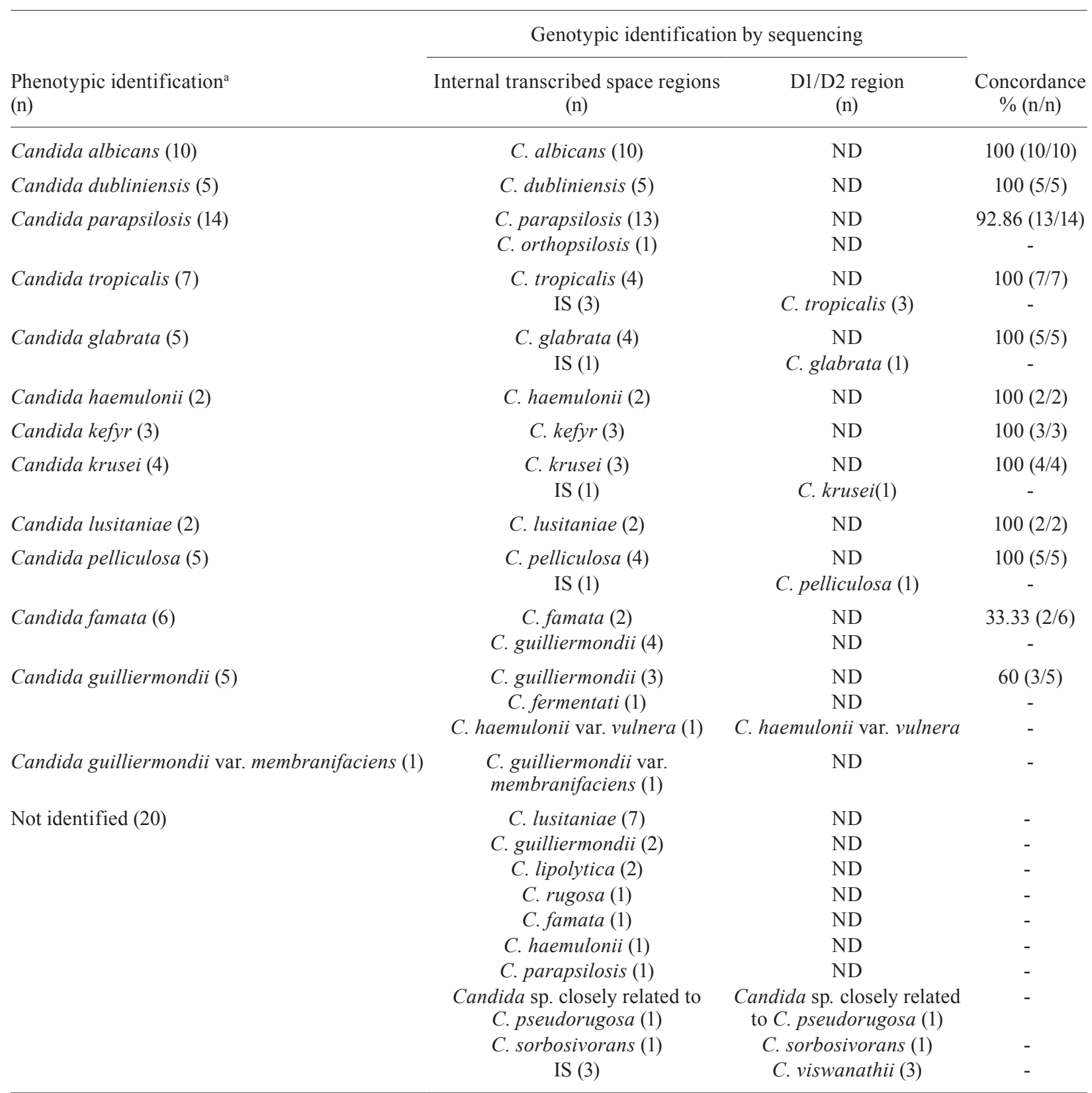

$a$ : number of microorganism from the culture collection of the Department of Mycology of the National Institute of Infectious Diseases Dr Carlos G Malbrán, Argentina; ND: not determined; IS: illegible sequence.

ITS sequence. In such cases, sequencing of the D1/D2 region was performed, resulting in a legible sequence of that domain, likely because the 26S rDNA has evolved slowly and is more conserved than the ITS regions.

Second, it is often assumed that fungal intraspecies variability in the ITS regions is generally low and represented by a percentage interval of $0-3 \%$ (Ciardo et al. 2006, Nilsson et al. 2008). In a large study of the sequences of the ITS regions available in international sequence databases, Nilsson et al. (2008) determined that the canonical 3\% threshold value for intraspecies variation is surprisingly accurate for fungi, but this threshold is nevertheless refuted by multiple examples from all of the fungal phyla. However, the authors calculated that the weighted average of the intraspecies ITS variability of the kingdom Fungi is $2.51 \pm 4.57 \%$ (1.96 $\pm 3.73 \%$ for Ascomycota), demonstrating the apparent futility of identifying a single unifying yet stringent fungus-wide cut-off value to demarcate ITS intraspecies variability from interspecies variability. In connection with the D1/ 


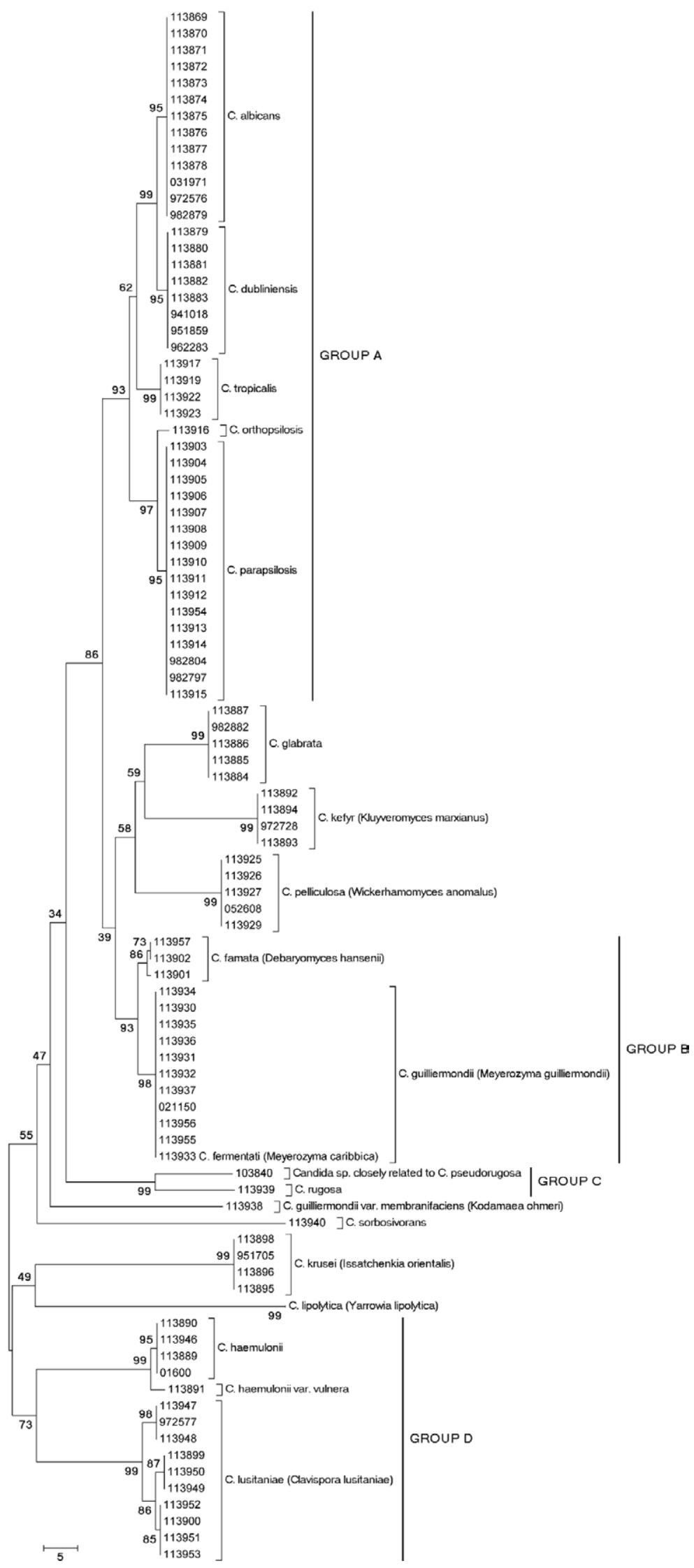

Neighbour joining tree based on the internal transcribed space regions sequences showing the phylogenetic relationship among Candida species and isolates. Bootstrap percentages from 2,000 replicates are shown in each node. Scale bar indicates number of differences. The teleomorph name correspondent to each anamorph Candida species is included between brackets. 
D2 region of the 26S rDNA sequence, Kurtzman (2006) showed that species strains exhibit no more than zerothree nucleotide differences $(0-0.5 \%)$ in this domain and strains showing six or more noncontiguous substitutions (1\%) are typically considered separate species. However, certain species exhibit an intraspecies variability of $>$ $1 \%$ (Lachance et al. 2003, Tavanti et al. 2005, VaughanMartini et al. 2005, Kurtzman 2006). In the current study, isolate 103840 showed $<97 \%$ similarity to the sequences of the ITS regions in the public databases. Isolate 103840 was first reported following a case of bloodstream infection and was identified as a Candida species closely related to C. pseudorugosa (Taverna et al. 2012). The present study indicates that this isolate may belong to a species that is more polymorphic than other species or may be distinct from previously identified strains.

Third, several public databases and bioinformatics tools currently greatly aid genotypic identification by sequencing. GenBank, the most popular of the public databases, contains numerous sequences, including those of fungal rDNA. The drawbacks of GenBank include the presence of certain sequencing and nomenclature errors and infrequent nomenclature updates and expert-based reclassifications of mislabelled sequences. In this context, other databases comprising well-characterised sequences are preferable. For example, the CBS Yeast Database contains results for roughly 6,500 strains available from the CBS collection, as well as descriptions of up to 900 yeast species (Pincus et al. 2007). However, GenBank contains sequences of novel species from around the world. As a consequence, in certain cases, it may be useful to consult both databases. In our study, the identification of isolate 103940 as C. sorbosivorans necessitated such a dual analysis. Notably, although isolate 103940 C. sorbosivorans was obtained from a blood sample, this species had never been reported as a human pathogen. Unfortunately, we do not have follow-up information on the case, so nothing further can be reported.

Based on our comparative analysis of methods of phenotypic and genotypic identification, seven isolates were found to have been misidentified by phenotypic identification. These isolates corresponded to species that share a phenotypic profile with other species or that are cryptic species (Tavanti et al. 2005, Vaughan-Martini et al. 2005, Desnos-Ollivier et al. 2008, CendejasBueno et al. 2012). Additionally, a phylogenetic analysis revealed a close relationship between the misidentified species, consistent with previous studies (Tavanti et al. 2005, Vaughan-Martini et al. 2005, Cendejas-Bueno et al. 2012, Taverna et al. 2012). The phylogenetic tree also indicated four well-supported groups. Group A comprised the species most frequently isolated in humans, all of which have no known teleomorph, but occur within the Lodderomyces clade, as proposed by others (Kurtzman \& Suzuki 2010). Group B was composed of members of the Debaryomyces and Meyerozyma genera that are difficult to discriminate by phenotypic methods (Nishikawa et al. 1999, Vaughan-Martini et al. 2005, Desnos-Ollivier et al. 2008, Castanheira et al. 2012). Group C was composed of a potentially new Candida species closely related to C. pseudorugosa and C. rugosa. Finally, Group D was formed of members of the C. haemulonii complex and C. lusitaniae. The high level of sequence diversity within the $C$. haemulonii complex has been previously studied, leading to reclassification (Cendejas-Bueno et al. 2012). In contrast, the high level of sequence diversity of C. lusitaniae is in agreement with the unusually polymorphic sequences of the D1/D2 region in these strains (Lachance et al. 2003). Further studies focussing on a reclassification of the C. lusitaniae complex should be pursued.

The concept of a barcode marker for fungi has been discussed in recent years. The ITS regions have demonstrated the highest probability of successful identification for the broadest range of fungi, with the most clearly defined barcode gap between interspecies and intraspecies variation and high ITS PCR amplification success (Schoch et al. 2012). The possibility of a two-marker barcoding system for fungi, as previously adopted for plants, is often discussed among mycologists and particularly those researching ascomycetous yeasts who prefer a system combining ITS and 26S rDNA sequences. Additionally, the concept of one fungus having one name, whether the fungus exhibits sexual reproduction, instead of dual fungal nomenclature has been integrated into the new International Code of Nomenclature for algae, fungi and plants (Taylor 2011).

In the present study, a phylogenetic analysis was performed based on a single marker. However, singlegene analyses do not yield sufficient information to resolve the phylogenies. Well-resolved phylogenies often include not only rDNA genes, but also protein-coding genes (Kurtzman \& Robnett 2003, Rokas et al. 2003, Diezmann et al. 2004, Suh et al. 2006, Tsui et al. 2008, Schoch et al. 2012). Other molecular studies have demonstrated that sequencing multiple genes or portions of genes and analysing the resultant data by phylogenetic methods is a robust strategy for identifying fungal species. This strategy is known as Genealogical Concordance Phylogenetic Species Recognition (Taylor et al. 2000). However, such a methodology is expensive and requires phylogenetic expertise, which may be limiting factors in clinical laboratories in which rapid identification is required (Balajee et al. 2009).

In conclusion, genotypic identification allowed the accurate identification of species frequently misidentified by phenotypic methods, cryptic species and potential new species. Yet, phenotypic data should not be disregarded and yeast identification should encompass a comprehensive analysis of both phenotypic and genotypic data.

\section{REFERENCES}

Abi-Said D, Anaissie E, Uzun O, Raad I, Pinzcowski H, Vartivarian S 1997. The epidemiology of hematogenous candidiasis caused by different Candida species. Clin Infect Dis 24: 1122-1128.

Alvarez I, Wendel JF 2003. Ribosomal ITS sequences and plant phylogenetic inference. Mol Phylogenet Evol 29: 417-434.

Balajee SA, Borman AM, Brandt ME, Cano J, Cuenca-Estrella M, Dannaoui E, Guarro J, Haase G, Kibbler CC, Meyer W, O’Donnell K, Petti CA, Rodriguez-Tudela JL, Sutton D, Velegraki A, Wickes BL 2009. Sequence-based identification of Asper- 
gillus, Fusarium and Mucorales species in the clinical mycology laboratory: where are we and where should we go from here? $J$ Clin Microbiol 47: 877-884.

Bosco-Borgeat ME, Taverna CG, Cordoba S, Isla MG, Murisengo OA, Szusz W, Vivot W, Davel G 2011. Prevalence of Candida dubliniensis fungemia in Argentina: identification by a novel multiplex PCR and comparison of different phenotypic methods. Mycopathologia 172: 407-414.

Castanheira M, Woosley LN, Diekema DJ, Jones RN, Pfaller MA 2012. Candida guilliermondii and other species of Candida misidentified as Candida famata: assessment by the Vitek 2, DNASequencing Analysis and MALDI-TOF MS in two global antifungal surveillance programs. J Clin Microbiol 51: 117-124.

Cendejas-Bueno E, Kolecka A, Alastruey-Izquierdo A, Theelen B, Groenewald M, Kostrzewa M, Cuenca-Estrella M, Gómez-López A, Boekhout T 2012. Reclassification of the Candida haemulonii complex, C. duobushaemulonii sp. nov. (C. haemulonii group II) and $C$. haemulonii var. vulnera var. nov.: two multiresistant human pathogenic yeasts. J Clin Microbiol 50: 3641-3651.

Ciardo DE, Schar G, Bottger EC, Altwegg M, Bosshard PP 2006. Internal transcribed spacer sequencing versus biochemical profiling for identification of medically important yeasts. J Clin Microbiol 44: 77-84.

Cordoba S, Vivot W, Bosco-Borgeat ME, Taverna C, Szusz W, Murisengo O, Isla G, Davel G, RNLM 2011. Species distribution and susceptibility profile of yeast isolated from blood cultures: results of a multicenter active laboratory-based surveillance study in Argentina. Rev Argent Microbiol 43: 176-185.

Desnos-Ollivier M, Ragon M, Robert V, Raoux D, Gantier JC, Dromer F 2008. Debaryomyces hansenii (Candida famata), a rare human fungal pathogen often misidentified as Pichia guilliermondii (Candida guilliermondii). J Clin Microbiol 46: 3237-3242.

Diezmann S, Cox CJ, Schönian G, Vilgalys RJ, Mitchell TG 2004. Phylogeny and evolution of medical species of Candida and related taxa: a multigenic analysis. J Clin Microbiol 42: 5624-5635.

Edmond MB, Wallace SE, McClish DK, Pfaller MA, Jones RN, Wenzel RP 1999. Nosocomial bloodstream infections in United States hospitals: a three-year analysis. Clin Infect Dis 29: 239-244.

Ellepola AN, Morrison CJ 2005. Laboratory diagnosis of invasive candidiasis. J Microbiol 43 (Suppl.): 65-84.

Falagas ME, Roussos N, Vardakas KZ 2010. Relative frequency of albicans and the various non-albicans Candida spp among candidemia isolates from inpatients in various parts of the world: a systematic review. Int J Infect Dis 14: e954-966.

Fell JW, Boekhout T, Fonseca A, Scorzetti G, Statzell-Tallman A 2000. Biodiversity and systematics of basidiomycetous yeasts as determined by large-subunit rDNA D1/D2 domain sequence analysis. Int J Syst Evol Microbiol 50: 1351-1371.

Hajjeh RA, Sofair AN, Harrison LH, Lyon GM, Arthington-Skaggs BA, Mirza SA, Phelan M, Morgan J, Lee-Yang W, Ciblak MA, Benjamin LE, Sanza LT, Huie S, Yeo SF, Brandt ME, Warnock DW 2004. Incidence of bloodstream infections due to Candida species and in vitro susceptibilities of isolates collected from 1998 to 2000 in a population-based active surveillance program. J Clin Microbiol 42: 1519-1527.

Hall TA 1999. BioEdit: a user-friendly biological sequence aligment editor and analysis program for windows 95/98/NT. Nucleic Acids Symp Ser 41: 95-98.

Iwen PC, Hinrichs SH, Rupp ME 2002. Utilization of the internal transcribed spacer regions as molecular targets to detect and identify human fungal pathogens. Med Mycol 40: 87-109.

Kurtzman CP 2006. Yeast species recognition from gene sequence analyses and other molecular methods. Mycoscience 47: 65-71.
Kurtzman CP 2010. Description of new yeast species - is one strain enough? The Bulletin of BISMiS 1: 17-24.

Kurtzman CP, Fell JW 1998. The yeast, a taxonomic study, 4th ed., Elsevier, New York, 1054 pp.

Kurtzman CP, Robnett CJ 1998. Identification and phylogeny of ascomycetous yeasts from analysis of nuclear large subunit (26S) ribosomal DNA partial sequences. Antonie Van Leeuwenhoek 73: 331-371.

Kurtzman CP, Robnett CJ 2003. Phylogenetic relationships among yeasts of the "Saccharomyces complex" determined from multigene sequence analyses. FEMS Yeast Res 3: 417-432.

Kurtzman CP, Suzuki M 2010. Phylogenetic analysis of ascomycete yeasts that form coenzyme Q-9 and the proposal of the new genera Babjeviella, Meyerozyma, Millerozyma, Priceomyces and Scheffersomyces. Mycoscience 51: 2-14.

Lachance MA, Daniel HM, Meyer W, Prasad GS, Gautam SP, Boundy-Mills K 2003. The D1/D2 domain of the large-subunit rDNA of the yeast species Clavispora lusitaniae is unusually polymorphic. FEMS Yeast Res 4: 253-258.

Latouche GN, Daniel HM, Lee OC, Mitchell TG, Sorrell TC, Meyer W 1997. Comparison of use of phenotypic and genotypic characteristics for identification of species of the anamorph genus Candida and related teleomorph yeast species. J Clin Microbiol 35: 3171-3180.

Möller EM, Bahnweg G, Sanderman H, Geiger HH 1992. A simple and efficient protocol for isolation of high molecular weigh DNA from filamentous fungi, fruit bodies and infected plant tissues. Nucleic Acids Res 20: 6115-6116.

Nguyen MH, Peacock Jr JE, Morris AJ, Tanner DC, Nguyen ML, Snydman DR, Wagener MM, Rinaldi MG, Yu VL 1996. The changing face of candidemia: emergence of non-Candida albicans species and antifungal resistance. Am J Med 100: 617-623.

Nilsson RH, Kristiansson E, Ryberg M, Hallenberg N, Larsson KH 2008. Intraspecific ITS variability in the kingdom fungi as expressed in the international sequence databases and its implications for molecular species identification. Evol Bioinform Online 4: 193-201.

Nishikawa A, Sugita T, Shinoda T 1999. Rapid identification of Debaryomyces hansenii/Candida famata by polymerase chain reaction. Med Mycol 37: 101-104.

Pfaller MA, Diekema DJ 2002. Role of sentinel surveillance of candidemia: trends in species distribution and antifungal susceptibility. J Clin Microbiol 40: 3551-3557.

Pfaller MA, Jones RN, Doern GV, Sader HS, Hollis RJ, Messer SA 1998. International surveillance of bloodstream infections due to Candida species: frequency of occurrence and antifungal susceptibilities of isolates collected in 1997 in the United States, Canada and South America for the SENTRY Program. The SENTRY Participant Group. J Clin Microbiol 36: 1886-1889.

Pincus DH, Orenga S, Chatellier S 2007. Yeast identification - past, present and future methods. Med Mycol 45: 97-121.

Price MF, LaRocco MT, Gentry LO 1994. Fluconazole susceptibilities of Candida species and distribution of species recovered from blood cultures over a 5-year period. Antimicrob Agents Chemother 38: 1422-1424.

Rodero L, Davel G, Soria M, Vivot W, Cordoba S, Canteros CE, Saporiti A 2005. Multicenter study of fungemia due to yeasts in Argentina. Rev Argent Microbiol 37: 189-195.

Rokas A, Williams BL, King N, Carroll SB 2003. Genome-scale approaches to resolving incongruence in molecular phylogenies. Nature 425: 798-804.

Schoch CL, Seifert KA, Huhndorf S, Robert V, Spouge JL, Levesque 
CA, Chen W, Fungal Barcoding Consortium 2012. Nuclear ribosomal internal transcribed spacer (ITS) region as a universal DNA barcode marker for Fungi. Proc Natl Acad Sci USA 109: 6241-6246.

Suh SO, Blackwell M, Kurtzman CP, Lachance MA 2006. Phylogenetics of Saccharomycetales, the ascomycete yeasts. Mycologia 98: 1006-1017.

Sullivan DJ, Henman MC, Moran GP, O'Neill LC, Bennett DE, Shanley DB, Coleman DC 1996. Molecular genetic approaches to identification, epidemiology and taxonomy of non-albicans Candida species. J Med Microbiol 44: 399-408.

Tamura K, Dudley J, Nei M, Kumar S 2007. MEGA4: Molecular Evolutionary Genetics Analysis (MEGA) software version 4.0. Mol Biol Evol 24: 1596-1599.

Tavanti A, Davidson AD, Gow NA, Maiden MC, Odds FC 2005. Candida orthopsilosis and Candida metapsilosis spp nov. to replace Candida parapsilosis groups II and III. J Clin Microbiol 43: 284-292.

Taverna CG, Córdoba S, Isla G, Fernández N, García S, Mazza M, Murisengo OA, Vivot W, Szusz W, Davel G, Tiraboschi IN, Bosco-Borgeat ME 2012. First case report of bloodstream infection due to a Candida species closely related to the novel species Candida pseudorugosa. J Clin Microbiol 50: 2165-2169.

Taylor JW 2011. One fungus = one name: DNA and fungal nomenclature twenty years after PCR. IMA Fungus 2: 113-120.

Taylor JW, Jacobson DJ, Kroken S, Kasuga T, Geiser DM, Hibbett
DS, Fisher MC 2000. Phylogenetic species recognition and species concepts in Fungi. Fungal Genet Biol 31: 21-32.

Thompson JD, Higgins DG, Gibson TJ 1994. CLUSTALW: improving the sensitivity of progressive multiple sequence alignment through sequence weighting, position-specific gap penalties and weight matrix choice. Nucleic Acids Res 22: 4673-4680.

Trick WE, Fridkin SK, Edwards JR, Hajjeh RA, Gaynes RP 2002. Secular trend of hospital-acquired candidemia among intensive care unit patients in the United States during 1989-1999. Clin Infect Dis 35: 627-630.

Tsui CK, Daniel HM, Robert V, Meyer W 2008. Re-examining the phylogeny of clinically relevant Candida species and allied genera based on multigene analyses. FEMS Yeast Res 8: 651-659.

Vaughan-Martini A, Kurtzman CP, Meyer SA, O’Neill EB 2005. Two new species in the Pichia guilliermondii clade: Pichia caribbica sp. nov., the ascosporic state of Candida fermentati and Candida carpophila comb. nov. FEMS Yeast Res 5: 463-469.

White TJ, Bruns T, Lee S, Taylor JW 1990. Amplification and direct sequencing of fungal ribosomal RNA genes for phylogenetics. In MA Innis, DH Gelfand, JJ Sninsky, TJ White, PCR protocols: a guide to methods and applications, Academic Press, New York, p. 315-322.

Wisplinghoff H, Bischoff T, Tallent SM, Seifert H, Wenzel RP, Edmond MB 2004. Nosocomial bloodstream infections in US hospitals: analysis of 24,179 cases from a prospective nationwide surveillance study. Clin Infect Dis 39: 309-317. 
TABLE

Reference strains and isolates, phenotypic and genotypic identification and GenBank accessions

Genotypic identification by sequencing

Phenotypic identification

(n)

Candida albicans (13)

Candida dubliniensis (8)

Candida glabrata (6)

Candida kefyr (4)

Candida haemulonii (3)

\begin{tabular}{|c|c|c|c|c|c|}
\hline & 113884 & C. glabrata & JN008125 & ND & - \\
\hline & 113885 & C. glabrata & JN008126 & ND & - \\
\hline & 113886 & C. glabrata & JN008127 & ND & - \\
\hline & 113887 & C. glabrata & JN008128 & ND & - \\
\hline & 113888 & IS & - & C. glabrata & JN032660 \\
\hline \multirow[t]{3}{*}{ Candida haemulonii (3) } & 01600 (CNM-CL-4098) & C. haemulonii & JN008144 & ND & - \\
\hline & 113889 & C. haemulonii & JN008145 & ND & - \\
\hline & 113890 & C. haemulonii & JN008146 & ND & - \\
\hline \multirow[t]{4}{*}{ Candida kefyr (4) } & $972728\left(\mathrm{RS}^{a}\right)$ & C. kefyr & JN008151 & ND & - \\
\hline & 113892 & C. kefyr & JN008149 & ND & - \\
\hline & 113893 & C. kefyr & JN008152 & ND & - \\
\hline & 113894 & C. kefyr & JN008150 & ND & - \\
\hline \multirow[t]{5}{*}{ Candida krusei (5) } & 951705 (ATCC 6258) & C. krusei & JN008156 & ND & - \\
\hline & 113895 & C. krusei & JN008153 & ND & - \\
\hline & 113896 & C. krusei & JN008154 & ND & - \\
\hline & 113897 & IS & - & C. krusei & JN032661 \\
\hline & 113898 & C. krusei & JN008155 & ND & - \\
\hline
\end{tabular}

\section{DMic}

(n)

Internal transcribed space regions 
Genotypic identification by sequencing

Phenotypic identification

DMic

(n)

(n)

Internal transcribed space regions

D1/D2 region

\begin{tabular}{|c|c|c|c|c|c|}
\hline & & Specie & $\begin{array}{l}\text { GenBank } \\
\text { accession }\end{array}$ & Specie & $\begin{array}{l}\text { GenBank } \\
\text { accession }\end{array}$ \\
\hline \multirow[t]{4}{*}{ Candida lusitaniae (4) } & 972577 (ATCC 200953) & C. lusitaniae & JN008161 & ND & - \\
\hline & 972578 (CNM-CL-1844) & IS & - & C. lusitaniae & JN032662 \\
\hline & 113899 & C. lusitaniae & JN008166 & ND & - \\
\hline & 113900 & C. lusitaniae & JN008158 & ND & - \\
\hline \multirow[t]{16}{*}{ Candida parapsilosis (16) } & $982797\left(\mathrm{RS}^{a}\right)$ & C. parapsilosis & JN016728 & ND & - \\
\hline & 982804 (ATCC 22019) & C. parapsilosis & JN016727 & ND & - \\
\hline & 113903 & C. parapsilosis & JN016716 & ND & - \\
\hline & 113904 & C. parapsilosis & JN016717 & ND & - \\
\hline & 113905 & C. parapsilosis & JN016730 & ND & - \\
\hline & 113906 & C. parapsilosis & JN016718 & ND & - \\
\hline & 113907 & C. parapsilosis & JN016719 & ND & - \\
\hline & 113908 & C. parapsilosis & JN016731 & ND & - \\
\hline & 113909 & C. parapsilosis & JN016720 & ND & - \\
\hline & 113910 & C. parapsilosis & JN016721 & ND & - \\
\hline & 113911 & C. parapsilosis & JN016723 & ND & - \\
\hline & 113912 & C. parapsilosis & JN016722 & ND & - \\
\hline & 113913 & C. parapsilosis & JN016725 & ND & - \\
\hline & 113914 & C. parapsilosis & JN016726 & ND & - \\
\hline & 113915 & C. parapsilosis & JN016729 & ND & - \\
\hline & 113916 & C. orthopsilosis & JN016732 & ND & - \\
\hline \multirow[t]{9}{*}{ Candida tropicalis (9) } & 982884 (ATCC 750) & IS & - & C. tropicalis & JN031578 \\
\hline & 031851 (ATCC 200956) & IS & - & C. tropicalis & JN031574 \\
\hline & 113917 & C. tropicalis & JN016733 & ND & - \\
\hline & 113918 & IS & - & C. tropicalis & JN031575 \\
\hline & 113919 & C. tropicalis & JN016734 & ND & - \\
\hline & 113920 & IS & - & C. tropicalis & JN031576 \\
\hline & 113921 & IS & - & C. tropicalis & JN031577 \\
\hline & 113922 & C. tropicalis & JN016736 & ND & - \\
\hline & 113923 & C. tropicalis & JN016735 & ND & - \\
\hline \multirow[t]{6}{*}{ Candida pelliculosa (6) } & $052608\left(\mathrm{RS}^{a}\right)$ & C. pelliculosa & JN016740 & ND & - \\
\hline & 113925 & C. pelliculosa & JN016737 & ND & - \\
\hline & 113926 & C. pelliculosa & JN016738 & ND & - \\
\hline & 113927 & C. pelliculosa & JN016739 & ND & - \\
\hline & 113928 & IS & - & C. pelliculosa & JN031571 \\
\hline & 113929 & C. pelliculosa & JN016741 & ND & - \\
\hline \multirow[t]{6}{*}{ Candida guilliermondii (6) } & $021150\left(\mathrm{RS}^{a}\right)$ & C. guilliermondii & JN008137 & ND & - \\
\hline & 113930 & C. guilliermondii & JN008131 & ND & - \\
\hline & 113931 & C. guilliermondii & JN008134 & ND & - \\
\hline & 113932 & C. guilliermondii & JN008135 & ND & - \\
\hline & 113933 & C. fermentati & JN021668 & ND & - \\
\hline & 113891 & $\begin{array}{c}\text { C. haemulonii } \\
\text { var. vulnera }\end{array}$ & JN008148 & $\begin{array}{l}\text { C. haemulonii } \\
\text { var. vulnera }\end{array}$ & JN031572 \\
\hline
\end{tabular}


Genotypic identification by sequencing

\begin{tabular}{|c|c|c|c|c|c|}
\hline \multirow[t]{2}{*}{$\begin{array}{l}\text { Phenotypic identification } \\
\text { (n) }\end{array}$} & \multirow[t]{2}{*}{$\begin{array}{l}\text { DMic } \\
\text { (n) }\end{array}$} & \multicolumn{2}{|c|}{ Internal transcribed space regions } & \multicolumn{2}{|c|}{ D1/D2 region } \\
\hline & & Specie & $\begin{array}{l}\text { GenBank } \\
\text { accession }\end{array}$ & Specie & $\begin{array}{l}\text { GenBank } \\
\text { accession }\end{array}$ \\
\hline \multirow[t]{6}{*}{ Candida famata (6) } & 113934 & C. guilliermondii & JN008130 & ND & - \\
\hline & 113935 & C. guilliermondii & JN008132 & ND & - \\
\hline & 113936 & C. guilliermondii & JN008133 & ND & - \\
\hline & 113937 & C. guilliermondii & JN008136 & ND & - \\
\hline & 113901 & C. famata & JN008140 & ND & - \\
\hline & 113902 & C. famata & JN008142 & ND & - \\
\hline $\begin{array}{l}\text { Candida guillermondii var. } \\
\text { membranifaciens (1) }\end{array}$ & 113938 & $\begin{array}{l}\text { C. guilliermondii } \\
\text { var. } \\
\text { membranifaciens }\end{array}$ & JN008143 & ND & - \\
\hline \multirow[t]{20}{*}{ Not identified (20) } & 113939 & C. rugosa & JN021671 & ND & - \\
\hline & 103840 & $\begin{array}{l}\text { Candida sp. } \\
\text { closely related to } \\
\text { C. pseudorugosa }\end{array}$ & JF345212 & $\begin{array}{c}\text { Candida sp. } \\
\text { closely related to } \\
\text { C. pseudorugosa }\end{array}$ & JF345218 \\
\hline & 113940 & C. sorbosivorans & JN021672 & C. sorbosivorans & JN031573 \\
\hline & 113941 & C. lipolytica & JN021670 & ND & - \\
\hline & 113942 & C. lipolytica & JN021669 & ND & - \\
\hline & 113943 & IS & - & C. viswanathii & JN031568 \\
\hline & 113944 & IS & - & C. viswanathii & JN031570 \\
\hline & 113945 & IS & - & C. viswanathii & JN031569 \\
\hline & 113946 & C. haemulonii & JN008147 & ND & - \\
\hline & 113947 & C. lusitaniae & JN008163 & ND & - \\
\hline & 113948 & C. lusitaniae & JN008162 & ND & - \\
\hline & 113949 & C. lusitaniae & JN008165 & ND & - \\
\hline & 113950 & C. lusitaniae & JN008164 & ND & - \\
\hline & 113951 & C. lusitaniae & JN008159 & ND & - \\
\hline & 113952 & C. Iusitaniae & JN008157 & ND & - \\
\hline & 113953 & C. lusitaniae & JN008160 & ND & - \\
\hline & 113954 & C. parapsilosis & JN016724 & ND & - \\
\hline & 113955 & C. guilliermondii & JN008139 & ND & - \\
\hline & 113956 & C. guilliermondii & JN008138 & ND & - \\
\hline & 113957 & C. famata & JN008141 & ND & - \\
\hline
\end{tabular}

$a$ : reference strain (RS) of the culture collection of the Department of Mycology of the National Institute of Infectious Diseases Dr Carlos G Malbrán, Argentina (DMic); ND: not determined; IS: illegible sequence. 